\title{
EFFECT OF PACKING TECHNIQUE AND CURING TIME ON THE MARGINAL SEALING AND SURFACE HARDNESS OF TWO BULK-FILL RESIN COMPOSITES
}

\author{
Marwa Mohamed Abbas Temirek*
}

\begin{abstract}
Recent advances in dental resin based restorative materials have given rise to development of composites for bulk placement, to replace the need for incremental layering. Clinical consequences of microleakage are secondary caries, pulp inflammation, marginal discoloration, postoperative sensitivity, and the longevity of filling. Surface hardness is one of the mechanical properties of the restoration that should always be taken into account, particularly when they are faced with large areas of heavy masticatory forces. Accordingly, the current study was conducted to investigate the effect of packing technique and curing time on the marginal sealing and surface hardness of two bulk fill resin composites.
\end{abstract}

Standardized class II proximal box cavities were prepared on the mesial and distal surface of the selected premolar teeth with the total of 48 cavities. The prepared cavities were randomly divided into 2 main groups, 24 cavities each, according to the placement technique used for cavity restoration either placement of bulkfill single increment of $4 \mathrm{~mm}$ depth or incremental placement of two increments of $2 \mathrm{~mm}$ each. Each group was subdivided into 2 subgroups, 12 cavities each, according to the bulk fill composite resin used; X-trafil bulkfill composite and Quixfil bulkfill composite. These subgroups were then subdivided into two smaller groups, 6 cavities each, according to the curing times either curing for 10 seconds following the manufacturers' instructions or curing for 20 seconds.

For all specimens, after bonding procedures, bulk-fill resin composites were manipulated and applied in cavities as the previously assigned methodology, specimens were then immersed in $2 \%$ methylene blue dye for 24 hours. Teeth were sectioned and viewed under a binocular stereomicroscope. Readings were recorded.

A total of 80 cylindrical resin composite specimens were prepared. samples were divided into 4 groups according to the type of bulk fill composite (X-tra fil or Quixfil) and irradiation time (10s or 20s). The resin composite was applied in the mold, covered with mylar strips and light cured using LED light curing unit with an intensity of $1200 \mathrm{~mW} / \mathrm{cm} 2$. Vickers Microhardness tester was used with microindentation carried out using a load of $500 \mathrm{~g}$. Three readings for each surface were taken and an average reading was calculated.

\footnotetext{
* Lecturer of Conservative Dentistry, Faculty of dentistry, Fayuom University.
} 


\begin{abstract}
X-trafil bulkfill composite showed significantly lower degree of leakage than Quixfil bulkfill composite. No significant difference in microleakage was shown between different curing times nor different application techniques. X-trafil bulkfill composite showed significantly higher microhardness than Quixfil bulkfill composite Curing for 10 seconds showed significantly higher microhardness. Bulk-fill single increment of $4 \mathrm{~mm}$ recorded significantly higher microhardness value. Within the limitations of the current study, we can conclude that 4-mm bulk fill packing of bulkfill composite resin, cured for 10 seconds, had adequate marginal sealing performance. Surface microhardness of bulkfill composite resin packed at 4-mm bulk fill, cured for 10 seconds, is acceptable.
\end{abstract}

KEY WORDS: bulkfill composite, microleakage, microhardness.

\section{INTRODUCTION}

Resin-based composites have been effectively used in dentistry for several years and widely substituted amalgam as a posterior restorations (Lazarchik, et al, 2007). Composite resins are considered materials of choice in modern restorative dentistry because of the increasing demand for high-quality aesthetic restorations in every day practice. Despite the continuous evolution of these resin materials, problems such as polymerization shrinkage and marginal microleakage still occur. Furthermore, with high-viscosity resins; it is difficult to gain perfect adaptation to internal cavity walls and proper marginal seal of the cavity (Ibrahim, et al, 2018)

The chief reasons for clinical failure of resin composite restorations are secondary caries and bulk fractures (Moraes \& Opdam, 2011). The previous reasons are related to early gap development and consequent degradation of the exposed surfaces involved in restoration bonding: dentin, adhesive and composite itself.

The most critical factors determining preservation of restoration placed in a cavity are the marginal seal and lack of leakage. A marginal microleakage first defined by Kidd in 1976 is a process involving clinically undetectable penetration of bacteria, their metabolites, enzymes, toxins, ions, and other cariogenic factors between the filling and the cavity wall. Clinical consequences of microleakage are secondary caries, pulp inflammation, marginal discoloration, postoperative sensitivity, and the $n$ of longevity of filling. It is supposed that the existing occlusive load of the oral cavity and the thermal variations favor the formation of a marginal gap at the contact surface between the tooth and material. When wide cavities are filled in posterior teeth, such a treatment can also imply the risk of incorporating air bubbles or contaminants. (Miros, et al, 2015)

Gap formation is accompanied with volumetric changes in resin-based materials resulting from polymerization shrinkage stress (PS) during polymerization at the bonded interface. Incremental filling techniques have been proposed to optimize composite polymerization and its internal marginal adaptation, using either 2-mm-thick oblique or horizontal increments. These procedures are thought to minimize the final volumetric shrinkage of the material, and therefore reduce internal gap formation, (Ferracane, 2011). Clinically, however, incremental filling techniques are complex and require significant chair side time for restoration placement.

Recent advances in dental resin based restorative materials have given rise to development of composites for bulk placement, to replace the need for incremental layering (Leprince, et al, 2013). Manufacturers claim that these new composites display reduced volumetric shrinkage, lower PS, and increased depth of cure, allowing for single incremental placement in up to 4-mm thick layers. Bulk-fill composites thus have the potential advantages of simplifying clinical technique and saving time. Furthermore, bulk placement prevents void incorporation and contamination between 
composite layers, producing more compact fillings, (Par, et al, 2015). These advantages are possible because of the enhanced translucency of the bulk-fill composites, which allows greater light transmission (Bucuta \& Ilie, 2014). In addition, the formulation of these materials allows for modulation of the polymerization reaction by use of some special, stress-relieving monomers, the use of more reactive photo-initiators, and the incorporation of different types of fillers, such as pre-polymerized particles and fiberglass rod segments (Marin et al., 2015).

Surface hardness is one of the most significant properties used to compare restorative materials, and it means the resistance to permanent indentation or penetration (Mandikos, et al, 2001). It is a mechanical property of the restoration that should always be taken into account, particularly when they are faced with large areas of heavy masticatory forces. Substantial surface microhardness of the restoration is one of the main requirements specially in posterior stress-bearing areas. One of the most main factors that affect dental restoration is that it undergoes wear during function or while being cleaned. As wear is due to abrasion, surface hardness is an essential property. It is the mechanical property most regularly used to characterize the wear resistance of materials. A material that have a higher surface hardness, in general, considered to be more wear resistant (Abed, et al, 2015).

Accordingly, the current study was conducted to investigate the effect of packing technique and curing time on the marginal sealing and surface hardness of two bulk fill resin composites.

\section{MATERIALS AND METHODS}

Two commercially available bulk fill resin composites were used in the study, table (1).

\section{Microleakage Assessment (marginal sealing as- sessment):}

A total of 24 intact, caries free, freshly extracted for orthodontic reasons, permanent human premolar teeth were selected for the study. Immediately after extraction, teeth were thoroughly washed under running water to remove blood and mucous and then scaled by ultrasonic scaler to remove calculus and remnants of periodontal membrane. Teeth exhibiting any signs of caries, microcracks or any other defect were discarded. The teeth were then stored in normal saline solution at room temperature until being used.

The teeth to be prepared were mounted in plaster blocks. Standardized class II proximal box cavities were prepared on the mesial and distal surface of the selected premolar teeth with the total of 48 cavities.

TABLE (1): The materials used in the study

\begin{tabular}{|c|c|c|c|c|}
\hline \multirow{2}{*}{ Product } & \multirow{2}{*}{ Manufacturer } & \multicolumn{2}{|r|}{ Composition } & \multirow{2}{*}{ Patch Number } \\
\hline & & Matrix & Filler & \\
\hline $\mathrm{X}$-tra fil & $\begin{array}{l}\text { Voco, } \\
\text { Guxhaven, } \\
\text { Germany. }\end{array}$ & $\begin{array}{l}\text { Bis-GMA } \\
\text { UDMA } \\
\text { TEGDMA } \\
\end{array}$ & $\begin{array}{l}\text { Barium boron alumino silicate glass } \\
86 \% \text { by weight, }(70.1 \% \text { by volume }) \\
\text { Size }(0.05-10 \mu \mathrm{m})\end{array}$ & $888-658-2584$ \\
\hline Quixfil & $\begin{array}{l}\text { Densply, Konstanz, } \\
\text { Germany. }\end{array}$ & $\begin{array}{l}\text { Bis-EMA } \\
\text { UDMA TEGDMA } \\
\text { TMPTMA } \\
\text { TCB }\end{array}$ & $\begin{array}{l}\text { Strontium aluminum sodium fluoride } \\
\text { phosphate silicate glass } \\
86 \% \text { by weight ( } 66 \% \text { by volume) } \\
\text { Size }(1-10 \mu \mathrm{m})\end{array}$ & $302-422-4511$ \\
\hline $\begin{array}{l}\text { Bis-GM } \\
\text { TEGDM } \\
\text { TMPTM }\end{array}$ & $\begin{array}{l}\text { Bisphenol A diglycidy } \\
\text { Triethylene glycol di } \\
\text { Trimethylolpropane }\end{array}$ & $\begin{array}{l}\text { methacrylate } \\
\text { ethacylate } \\
\text { imethacrylate }\end{array}$ & $\begin{array}{l}\text { A: Urethane dimethacrylate } \\
\text { MA: Bisphenol-A polyethylene glycol } \\
\text { Tetracarboxylic acid bishydroxyethyl }\end{array}$ & $\begin{array}{l}\text { erdimethacrylate } \\
\text { hacrylate }\end{array}$ \\
\hline
\end{tabular}


Dimensions of class II box cavity were depth of $4 \mathrm{~mm}$ (occluso-gingivally), width of $2 \mathrm{~mm}$ (mesio-distally) and length of $2 \mathrm{~mm}$ (bucco-lingually). The cavities were standardized using a high speed carbide fissure bur with the same dimensions. Cavity preparations were done with water coolant. Burs were replaced every 6 preparations. The cavity margins were left unbevelled $\left(90^{\circ}\right.$ cavosurface angle). Following cavity preparation, the prepared teeth were stored in normal saline at room temperature until being restored.

The prepared cavities were randomly divided into 2 main groups, 24 cavities each, according to the placement technique used for cavity restoration $(\mathrm{P})$, whereas $\left(\mathrm{P}_{1}\right)$ denotes placement of bulkfill single increment of $4 \mathrm{~mm}$ depth and $\left(\mathrm{P}_{2}\right)$ denotes incremental placement of two increments of $2 \mathrm{~mm}$ each. Each group was subdivided into 2 subgroups, 12 cavities each, according to the bulk fill composite resin used $(\mathrm{M})$, whereas $\left(\mathrm{M}_{1}\right)$ denotes $\mathrm{X}$-trafil bulkfill composite and $\left(\mathrm{M}_{2}\right)$ denotes Quixfil bulkfill composite. These subgroups were then subdivided into two smaller groups, 6 cavities each, according to the curing times used $(T)$, where $\left(T_{1}\right)$ stands for curing for 10 seconds following the manufacturers' instructions and $\left(T_{2}\right)$ stands for curing for 20 seconds.

For all subgroup specimens, 37\% phosphoric acid etchant gel $^{*}$ was applied using its application syringe for 15 seconds, then rinsed and air dried until the walls have matt appearance. Universal bonding agent** was applied according to the manufacturers' instructions and cured for 20 seconds. After application of toflemire matrix band and holder, bulk-fill resin composites were manipulated and applied in cavities as the previously assigned methodology, following the different placement techniques and curing times, curing was performed from occlusal surface only.

Finishing and polishing of all restorations was done immediately using super fine diamond finishing stones ${ }^{* * *}$ and high speed contrangle handpiece ${ }^{* * * *}$ under water coolant. Then, further finishing and polishing using subsequent descending order (coarse, medium, fine, superfine) flexible discs ${ }^{* * * * *}$ was done. A pop-on mandrel fixed to a low speed contrangle handpiece ${ }^{* * * * * * *}$ was used to hold the discs in place. The teeth were stored in normal saline solution at room temperature for not more than one week. Each group was stored in a separate container with an assigned label.

The teeth were removed from saline and dried with oil free compressed air. The apices of the roots were sealed with modeling wax $^{* * * * * * *}$. One layer of nail varnish was applied on the surface of the teeth, except for the restoration and $1 \mathrm{~mm}$ around its margins and left to dry. A second layer was then applied and teeth were then wrapped individually with aluminum foil and adapted using a burnisher. The restoration and $1 \mathrm{~mm}$ around the restoration margins was exposed using a sharp scalpel. A final coat of nail varnish was then applied over the wrapped foil at the cut edges to ensure proper sealing.

The specimens were then immersed in $2 \%$ methylene blue dye for 24 hours. After removal from the dye, the specimens were washed under running water for 10 minutes. The foil was stripped off. The teeth were sectioned longitudinally in a mesio-distal direction through the middle of the restoration using a diamond disc rotating at low speed under sufficient water coolant so as to avoid overheating of the restoration.

\footnotetext{
* Densply, Konstanz, Germany.

** Universal adhesive system, 3M Oral Care Solutions Division, St. Paul, MN 55144-1000, USA

*** Dentamerica, U.S.A

***** Advance co.t 0611328 , U.S.A

***** 3M Soflex discs, Germany

*******Advance co. $\mathrm{t} 0611328$, U.S.A

******** Cavex
} 
To quantify the extent of microleakage at the occlusal and gingival walls, the specimens were viewed under a binocular stereomicroscope* connected to a personal computer. Image analysis for dye penetration was performed using an image analysis software**. Readings (in $\mathrm{mm}$ ) were recorded, tabulated and statistically analysed.

\section{Surface hardness assessment:}

A total of 80 cylindrical resin composite specimens were prepared, $6 \mathrm{~mm}$ in diameter and $4 \mathrm{~mm}$ in height, using a split Teflon mold. Following the variables of the study, the samples were divided into 4 groups according to the type of bulk fill composite (X-tra fil or Quixfil) and irradiation time (10s or 20s). The resin composite was applied in the mold, covered with mylar strips and light cured using LED light curing unit*** with an intensity of $1200 \mathrm{~mW} / \mathrm{cm} 2$. Specimens were then stored dry in light proof labeled containers for $24 \mathrm{~h}$ before testing. For microhardness testing, a Vickers Microhardness tester ${ }^{* * * *}$ was used with microindentation carried out using a load of $500 \mathrm{~g}$ and dwell time of 15s under 20X magnification scale. Top surfaces were measured for each specimen. Three readings for each surface were taken and an average reading was calculated. Data were recorded, tabulated and statistically analysed.

Data were statistically described in terms of mean \pm standard deviation $( \pm$ SD). Effect of the different independent factors as well as the interaction was tested through Multivariate Analysis of Variance (MANOVA) through General Linear Regression Model analysis. Correlation between various variables was done using Pearson moment correlation equation. $p$ values less than 0.05 was considered statistically significant. All statistical calculations were done using computer program IBM SPSS (Statistical Package for the Social Science; IBM Corp, Armonk, NY, USA) release 22 for Microsoft Windows

* SZ40 Olympus, Japan

** Image Tool for Windows Version 3

*** EliparTMS10, 3M ESPE, St. Paul, USA

**** Nexus 4000TM, INNOVTEST Europe BV, Borgharenweg, Netherlands

\section{RESULTS}

\section{Results for Microleakage assessment (marginal sealing assessment)}

Microleakage assessment readings mean values and standard deviations (SD) for composite materials investigated are presented in tables (2) \& (3), fig (1).

X-trafil bulkfill composite showed significantly lower degree of leakage $(0.12 \pm 0.211)$ than Quixfil bulkfill composite which showed leakage of $(0.29$ $\pm 0.663), P<0.05$. No significant difference was shown between different curing times. Curing for 10 seconds showed $(0.13 \pm 0.231)$, while curing for 20 seconds recorded $(0.28 \pm 0.659)$. $p=0.536$. No significant difference was shown between different application techniques. Bulk-fill single increment of $4 \mathrm{~mm}$ recorded mean microleakage values of $(0.23 \pm 0.665)$, while incremental placement of two increments of $2 \mathrm{~mm}$ each showed values of $(0.18 \pm 0.238)$ with no significant difference.

\section{Results for Surface Microhardness assessment:}

Microhardness assessment readings mean values and standard deviations (SD) for composite materials investigated are presented in tables (4) \& (5), fig (2).

X-trafil bulkfill composite showed significantly higher microhardness $(84.720 \pm 3.5381)$ than Quixfil bulkfill composite (72.660 \pm 4.8329), $P<0.05$. Curing for 10 seconds showed significantly higher microhardness $(79.813 \pm 7.9283)$ than curing for 20 seconds recorded $(77.568 \pm 6.7096), P$ value $<0.05$. Bulk-fill single increment of $4 \mathrm{~mm}$ recorded significantly higher microhardness value (79.758 $\pm 4.4155)$ than incremental placement of two increments of $2 \mathrm{~mm}$ each showed values of (77.623 $\pm 9.4142), P$ value $<0.05$ 
TABLE (2): Shows descriptive statistics (mean and standard deviation) for dependent variable, Microleakage

\begin{tabular}{|c|c|c|c|c|c|c|c|c|c|c|c|c|c|c|}
\hline Mat & Tech & Time & Mean & S. D. & Mat & Tech & Time & Mean & S.D. & Mat & Tech & Time & Mean & S. D. \\
\hline \multirow[t]{7}{*}{$X$} & \multirow[t]{2}{*}{ Bulk } & 10 & 0.08 & 0.201 & \multirow[t]{7}{*}{ Q } & \multirow[t]{2}{*}{ Bulk } & 10 & 0.09 & 0.112 & \multirow[t]{4}{*}{ Total } & Bulk & Total & 0.23 & 0.665 \\
\hline & & 20 & 0.00 & 0.000 & & & 20 & 0.75 & 1.197 & & Incr & Total & 0.18 & 0.238 \\
\hline & \multirow[t]{2}{*}{ Incr } & 10 & 0.15 & 0.275 & & \multirow[t]{2}{*}{ Incr } & 10 & 0.19 & 0.303 & & \multirow[t]{2}{*}{ Total } & 10 & 0.13 & 0.231 \\
\hline & & 20 & 0.24 & 0.204 & & & 20 & 0.14 & 0.165 & & & 20 & 0.28 & 0.659 \\
\hline & \multirow[t]{3}{*}{ Total } & 10 & 0.11 & 0.238 & & \multirow[t]{3}{*}{ Total } & 10 & 0.14 & 0.229 & & & & & \\
\hline & & 20 & 0.12 & 0.186 & & & 20 & 0.45 & 0.892 & & & & & \\
\hline & & Total & 0.12 & 0.211 & & & Total & 0.29 & 0.663 & & & & & \\
\hline
\end{tabular}

TABLE (3): shows tests of between-subjects effects for dependent variable, Microleakage

\begin{tabular}{|l|c|c|c|c|c|}
\hline Source & $\begin{array}{c}\text { Type III Sum } \\
\text { of Squares }\end{array}$ & $\mathrm{df}$ & $\begin{array}{c}\text { Mean } \\
\text { Square }\end{array}$ & $\mathrm{F}$ & $\mathrm{p}$ value \\
\hline Mat & 0.738 & 1 & 0.738 & 4.448 & $0.038^{*}$ \\
\hline Tech & 0.064 & 1 & 0.064 & 0.387 & 0.536 \\
\hline Time & 0.594 & 1 & 0.594 & 3.580 & 0.062 \\
\hline
\end{tabular}

$\mathrm{R}$ Squared $=.435($ Adjusted R Squared $=.329)$

$P$ value $<0.05$ is statistically significant

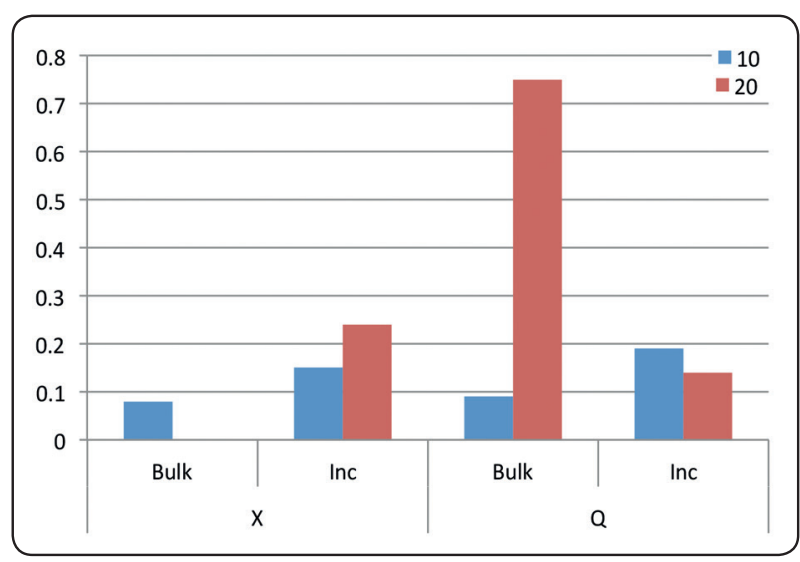

Fig. (1): A bar chart showing microleakage of bulk fill resin composites at different irradiation times using different techniques

\section{Results for Surface Microhardness assessment:}

TABLE (4): shows descriptive statistics (mean and standard deviation) for dependent variable, Microhardness

\begin{tabular}{|c|c|c|c|c|c|c|c|c|c|c|c|c|c|c|}
\hline Mat & Tech & Time & Mean & S.d. & Mat & Tech & Time & Mean & S.d. & Mat & Tech & Time & Mean & S.d. \\
\hline \multirow[t]{8}{*}{ X } & \multirow[t]{3}{*}{ Bulk } & 10 & 84.150 & 3.6421 & \multirow[t]{8}{*}{$\mathrm{Q}$} & \multirow[t]{3}{*}{ Bulk } & 10 & 75.910 & 1.5975 & \multirow[t]{8}{*}{ Total } & \multirow{2}{*}{ Bulk } & \multirow{2}{*}{ Total } & \multirow{2}{*}{79.758} & \multirow{2}{*}{4.4155} \\
\hline & & \multirow[t]{2}{*}{20} & \multirow{2}{*}{82.400} & \multirow{2}{*}{3.1394} & & & \multirow[t]{2}{*}{20} & \multirow{2}{*}{76.570} & \multirow{2}{*}{1.3712} & & & & & \\
\hline & & & & & & & & & & & Incr & Total & 77.623 & 9.4142 \\
\hline & \multirow[t]{2}{*}{ Incr } & 10 & 88.900 & 0.6912 & & \multirow[t]{2}{*}{ Incr } & 10 & 70.290 & 5.0747 & & \multirow{2}{*}{ Total } & 10 & 79.813 & 7.9283 \\
\hline & & 20 & 83.430 & 1.7442 & & & 20 & 67.870 & 3.2513 & & & 20 & 77.568 & 6.7096 \\
\hline & \multirow[t]{3}{*}{ Total } & 10 & 86.525 & 3.5281 & & \multirow[t]{3}{*}{ Total } & 10 & 73.100 & 4.6604 & & & & & \\
\hline & & 20 & 82.915 & 2.5276 & & & 20 & 72.220 & 5.0810 & & & & & \\
\hline & & Total & 84.720 & 3.5381 & & & Total & 72.660 & 4.8329 & & & & & \\
\hline
\end{tabular}


TABLE (5): Shows tests of between-subjects effects for dependent variable, Microhardness

\begin{tabular}{|l|c|c|c|c|c|}
\hline Source & Type III Sum of Squares & df & Mean Square & F & p value \\
\hline Mat & $2,908.872$ & 1 & $2,908.872$ & 345.286 & $0.000 *$ \\
\hline Tech & 91.164 & 1 & 91.164 & 10.821 & $0.002 *$ \\
\hline Time & 100.800 & 1 & 100.800 & 11.965 & $0.001 *$ \\
\hline $\begin{array}{l}\text { a. R Squared }=.859 \text { (Adjusted R Squared = 846) } \\
P \text { value }<0.05 \text { is statistically significant }\end{array}$
\end{tabular}

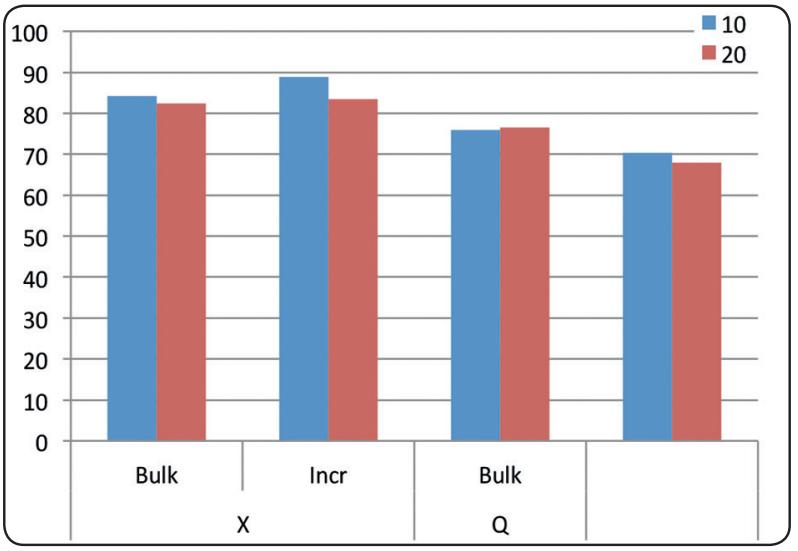

Fig. (2): A bar chart showing microhardness of bulk fill resin composites at different irradiation times using different techniques

\section{DISCUSSION}

Currently, there is a growing preferable trend among practitioners to use bulk-fill resin based composite materials because of their more simplified procedures. Manufacturers mentioned that the main advancement of bulk-fill composite materials, namely increased depth of cure, which probably results from higher translucency, and low polymerization shrinkage stress are related to modifications in the filler content and/or organic matrix with the help of advanced technology. Nowadays, bulk-fill resins are often preferred because of their clinical ease of use and time savings properties.
For sufficient polymerization, adequate light output, appropriate wavelength range of the light and exposure time. Other factors affect the depth of cure, including resin composite type, shade and translucency, increment thickness, distance from the tip of the light cure unit, post-irradiation period and size and distribution of filler particles. When the cavity is large, incremental layering can be used, with approximately $2 \mathrm{~mm}$ thick increments. This technique is used to avoid the depth of cure limitation and to reduce polymerization shrinkage effects. Insufficient polymerization may result in the degradation of the resin composite, poor physical properties and adverse biological reactions owing to the leaching of the monomeric components of the unset resin composite. There are various disadvantages associated with incremental techniques, such as incorporating voids or contamination between composite layers, failures in bonding between layers, placement difficulty owing to limited access in small cavities and an extended treatment time for placement of layers and their polymerization (Alrahlah, 2013)

One of the common failures of adhesive resin composite restorations is marginal leakage. Marginal leakage is related to several factors, such as dimensional changes of materials following polymerization shrinkage, thermal contractions, water sorption, and mechanical stresses

Successful adhesion to enamel and dentin is the main goal when restoring using adhesive resins. 
Although high quality adhesive systems have been recently introduced, they cannot guarantee perfect adhesion to tooth structure. Despite all developments in adhesive systems, polymerization shrinkage and marginal leakage remain the main cause of RBC failures. Restorations are affected directly by many factors such as cavity design, placement technique (layering versus bulk), curing mode and wavelength, the adhesive system used, water sorption of the RBC and shade and opacity of RBC (Alshaafi, M. M., 2017).

It is impossible to totally avoid marginal gaps and leakage between tooth interface and RBC's. It also has been stated that it is impossible to totally eliminate voids formed between the different layers of RBC's.

Incremental layering technique has been long accepted as a golden standard for placement of resin composite in cavity preparations to reduce the contraction gap along the margins. Though the incremental technique has many benefits, it has some disadvantages, the possibility of having voids or contamination between composite layers, the difficulty in placement especially in cases of limited access in conservative preparations and the increased time needed to place and polymerize each layer which is the most thing that concerns the patient

Innovations in the types and formulas of RBC's have recently claimed significant flow and low polymerization shrinkage values of new bulk fill RBC systems. These systems are marketed as RBC's having greater depth of cure that can be placed in a bulk fill technique ( $4 \mathrm{~mm}$ or $6 \mathrm{~mm}$ cavity) instead of the standard increments of $2 \mathrm{~mm}$.

Companies claim that these RBC systems reduce the amount of polymerization shrinkage and working time. This new technology and concept of these newer RBC systems was based on changing the monomer chemistry to create monomers with lower viscosity. The new changes in RBC systems was achieved by incorporating hydroxyl free Bis-GMA, aliphatic urethane dimethacrylates or partially aromatic urethane dimethacrylates or highly branched methacrylates. The new changes in the organic matrix of these new bulkfill RBCsystems showed significant reduction in the polymerization shrinkage values and stresses of 60\%-70\%. (Ferracane, J. L., 2011).

Bulk fill resin composite materials feature a characteristic thing being with low polymerization shrinkage with subsequent decrease in shrinkage stress while preserving proper curing at a 4-mm increment thickness. So, whether inserted incrementally or in bulk, less stresses happened leading to maintaining marginal continuity (E, Abdlaziz, et al., 2017).

In accordance to previous findings, the bulk fill resin composite materials tested in the current study allowed $4 \mathrm{~mm}$ increment thickness placement with low marginal leakage and better adaptation thanks to modifying their matrix and filler technology also their photo initiator. X-trafil bulkfill composite showed significantly lower degree of leakage than Quixfil bulkfill composite, Xtra fil is a non-flowable bulk fill resin composite material; it is characterized by increased filler size so the refractive index of the fillers increases, approaching the refractive index of the polymer matrix. Therefore, light scattering is decreased and light transmission during curing increases. It presents with a universal shade with higher translucency. Variations in composition, different type and smaller fillers and higher filler loading were the possible causes of better performance and less microleakage readings of X-trafil bulkfill composite. The monomer composition might play a role in this finding, as the degree of conversion of Bis-EMA monomer is higher than that of Bis-GMA. (Elkorashy, M. E., 2016).

No significant difference was shown between different curing times application techniques, also 
(E, Abdlaziz, et al., 2017) claimed that bulk fill resin composite materials feature a characteristic thing being with low polymerization shrinkage with subsequent decrease in shrinkage stress while preserving proper curing at a 4-mm increment thickness. So, whether inserted incrementally or in bulk, less stresses happened leading to maintaining marginal continuity.

The manufacturers reported that curing for 10 s using light curing units with an intensity of $800 \mathrm{~mW} / \mathrm{cm} 2$ or more is sufficient for adequate polymerization of both resin composites used in the current study. However, numerous in vitro studies have recommended a minimum of 20 s curing time to properly polymerize resin composites to deeper layers. (Elkorashy, M. E., 2016), no significant difference in marginal leakage was shown between different curing times.

It is of principal importance for the longevity of resin composite restorations is to be adequately polymerized (Flury, et al., 2014), polymerization reaction leads to hardening of RBC's. The Vickers microhardness surface testing of resin composites has been used to evaluate indirectly the extent of polymerization. The present study, during preparation of samples, we used molds of Teflon, which absorbs much less light and allows the light emitted from the light-curing unit to pass to greater depths, and measured on specimens after storage of $24 \mathrm{~h}$.

In a previous study, (Eun-Ha Kim, et al., 2014), the same tendency of the microhardness decreasing as the resin thickness increased was observed. Regarding the amount of the hardness change, bulkfill resin composites, exhibited smaller changes in hardness according to the thickness, whereas regular resin composites, showed a drastic decrease in the $4 \mathrm{~mm}$ specimens. They stated that manufacturers recommend that $4 \mathrm{~mm}$ thick increments can be cured in a single step. Based on the results of their study, up to $4 \mathrm{~mm}$ thick increments of bulk-fill resin composites are clinically acceptable. These findings support the current results of our study, bulk fill resin composites showed significantly higher hardness with placement in $4 \mathrm{~mm}$ thickness and cured for 10 seconds following manufacturers' instructions.

\section{CONCLUSIONS}

Within the limitations of the current study, we can conclude that:

- 4-mm bulk fill packing of bulkfill composite resin, cured for 10 seconds, had adequate marginal sealing performance.

- Surface microhardness of bulkfill composite resin packed at 4-mm bulk fill, cured for 10 seconds, is acceptable.

- More studies need to be done to compare the longevity; the mechanical and physical properties of the different bulk fill materials in comparison with the conventional RBC's.

\section{REFERENCES}

- $\quad$ Abed, Y. A., Sabry, H. A., \& Alrobeigy, N. A. (2015). Science Direct Degree of conversion and surface hardness of bulk-fill composite versus incremental-fill composite. Tanta Dental Journal, 12(2), 71-80. https://doi.org/10.1016/j. tdj. 2015.01 .003

- Ahmed, M., \& Abouelnaga, A. (2014). A comparison of gingival marginal adaptation and surface microhardness of class II resin based composites (conventional and bulk fill) placed in layering versus bulk fill techniques.

- Alrahlah, A. A. (2013). Physical, Mechanical and Surface Properties of Dental Resin-composites.

- Alshaafi, M. M. (2017). Factors affecting polymerization of resin-based composites : A literature review. The Saudi Dental Journal, 29(2), 48-58. https://doi.org/10.1016/j. sdentj.2017.01.002

- Amer Tiba, PhD; Gregory G. Zeller, DDS, MS; Cameron Estrich, MPH; Albert Hong: A Laboratory Evaluation of Bulk-Fill Versus Traditional Multi-Increment-Fill ResinBased Composites ADA Professional Product Review: 2013 Volume 8• Issue 3

- Bucuta, S., \& Ilie, N. (2014). Light transmittance and micro-mechanical properties of bulk fill vs. conventional 
resin based composites. Clin Oral Invest, 18, 1991-2000. https://doi.org/10.1007/s00784-013-1177-y

- Christensen GJ. Remaining challenges with Class II resin-based composite restorations. J Am Dent Assoc. 2007;138(11):1487-1489.

- $\quad$ E, Abdlaziz, R., Gomaa, H. A., \& Haridy, M. F. (2017). Effect of two types of packing techniques on the marginal leakage of bulk, EDJ, 62(1), 1-4.

- Elkorashy, M. E. (2016). Water sorption and solubility of two bulkfill resin composites. Egyption Dental Journal, 62(1), 825-833.

- $\quad$ Eun-Ha Kim, K.-, Hwa Jung, S.-A., Son, Bock Hur, Y.-, Hoon Kwon, J.-, \& Park, K. (2014). Effect of resin thickness on the microhardness and optical properties of bulkfill resin composites. Restorative Dentistry and Endodontics, 7658(ISSN 2234), 1-8.

- Ferracane, J. L. (2011). Resin composite - State of the art. Dental Materials, 27, 29-38. https://doi.org/10.1016/j. dental.2010.10.020

- $\quad$ Flury, S., Peutzfeldt, A., \& Lussi, A. (2014). Influence of increment thickness on microhardness and dentin bond strength of bulk fill resin composites. Dental Materials, 30(10), 1104-1112. https://doi.org/10.1016/j.dental .2014 .07 .001

- Giachetti L, Scaminaci-Russo D, Bambi C, et al. A review of polymerization shrinkage stress: current techniques for posterior direct resin restorations. J Contemp Dent Pract. 2006;7(4):79-88.

- $\quad$ Ibrahim, H. A., Shalaby, M. E., \& Abdalla, A. I. (2018). Marginal fit of class II cavities restored with bulk - fill composites. Tanta Dental Journal, 15(1), 1-6. https://doi. org/10.4103/tdj.tdj

- Idriss S, Habib C, Abduljabbar T, et al. Marginal adaptation of class II resin composite restorations using incremental and bulk placement techniques: an ESEM study. J Oral Rehabil. 2003;30(10):1000-1007.

- Kanca J 3rd, Suh BI. Pulse activation: reducing resin-based composite contraction stresses at the enamel cavosurface margins. Am J Dent. 1999;12(3):107-112.

- $\quad$ Lazarchik, D. A., Hammond, B. D., Sikes, C. L., Looney, S. W., \& Frederick, A. (2007). Hardness comparison of bulk-filled / transtooth and incremental-filled / occlusally irradiated composite resins. The Journal of Prosthetic Dentistry, 98(2), 129-140.

- Leprince, J. G., Palin, W. M., Hadis, M. A., Devaux, J., \& Leloup, G. (2013). Progress in dimethacrylate-based dental composite technology and curing efficiency. Dental Materials, 29(2), 139-156. https://doi.org/10.1016/j.dental. 2012.11.005
- Lowe RA. The search for a low-shrinkage direct composite. Oral Health Journal. March 2010.

- Mackenzie L, Shortall AC, Burke FJ. Direct posterior composites: a practical guide. Dent Update. 2009; 36(2):71-72, 74-76,79-80 passim.

- Mandikos, M. N., Mcgivney, G. P., Davis, E., Bush, P. J., \& Carter, J. M. (2001). A comparison of the wear resistance and hardness of indirect composite resins. The Journal of Prosthetic Dentistry, 85(4), 386-395.

- Marin, B., Allen, F., Ruggiero, R., Mogilevych, B., Eduardo, L., Soares, S., ... Giannini, M. (2015). Monomer conversion , microhardness, internal marginal adaptation , and shrinkage stress of bulk-fill resin composites. Dental Materials, 31(12), 1542-1551. https://doi.org/10.1016/j. dental.2015.10.001

- Miros, B., Or, B., \& B, R. C. (2015). Evaluation of Marginal Integrity of Four Bulk-Fill Dental Composite Materials : In Vitro Study. The Scientific World Journal, 1-8. https:// doi.org/10.1155/2015/701262

- $\quad$ Moraes, R. R., \& Opdam, N. J. M. (2011). Longevity of posterior composite restorations: Not only a matter of materials. Dental Materials, 28(1), 87-101. https://doi. org/10.1016/j.dental.2011.09.003

- Quellet D. Considerations and techniques for multiple bulk-fill direct posterior composites. Compend Contin Educ Dent. 1995;16(12):1212-1226.

- Ruiz JL, Mitra S. Using cavity liners with direct posterior composite restorations. Compend Contin Educ Dent. 2006;27(6):347-351.

- Ruiz JL. Occlusal disease: restorative consequences and patient education. Dent Today. 2007; 26(9):90-95.

- Sarrett DC. Clinical challenges and the relevance of materials testing for posterior composite restorations. Dent Mater. 2005;21(1):9-20.

- Sawair FA, Hassoneh Y, Jamleh AO, et al. Observance of proper mercury hygiene practices by Jordanian general dental practitioners. Int $\mathrm{J}$ Occup Med Environ Health. 2010;23(1):47-54.

- $\quad$ Strength, B., Doyle, G., \& Murphy, D. (2000). Effects of Composite Thickness on. J Can Dent Assoc, 66(1), 35-39.

- Tarle, M. P. O. G. D. M. E. K. Z. (2015). Raman Spectroscopic Assessment of Degree of Conversion of BulkFill Resin Composites - Changes at 24 Hours Post Cure. Operative Dentistry, 40(3), E92-E101. https://doi. org/10.2341/14-091-L

- Van Ende A, De Munck J, Mine A, et al. Does a lowshrinking composite induce less stress at the adhesive interface? Dent Mater. 2010;26(3):215-222. 